\title{
E se também o Melanócito participasse na Fisiopatologia da Psoríase? E esta, hein?!
}

\author{
Tiago Torres \\ Assistente Hospitalar de Dermatovenereologia e Responsável pela Consulta de Psoríase/Consultant Dermatology and Venereology, \\ Responsible for the Psoriasis Outpatient Clinic, Serviço de Dermatologia Centro Hospitalar do Porto/Department of Dermatology, \\ Centro Hospitalar do Porto, Portugal \\ Assistente de Dermatologia do Mestrado Integrado em Medicina do Instituto de Ciências Biomédicas Abel Salazar, Universidade do \\ Porto/ Assistant Professor of Dermatology, University of Porto, Portugal
}

\section{Does the Melanocyte participate in the Pathogenesis of Psoriasis?}

\author{
KEY-WORDS - Melanocytes; Psoriasis/ physiopathology.
}

Nos últimos anos observaram-se importantes avanços no conhecimento da fisiopatologia da psoríase. Durante décadas, a psoríase foi vista como uma doença dos queratinócitos. ' Nos anos 80, o início da investigação clínica e translacional em humanos permitiu identificar vários mecanismos fisiopatológicos e alvos terapêuticos na psoríase, que conduziram ao desenvolvimento de inúmeras terapêuticas, que alteraram de forma drástica o tratamento dos doentes com psoríase. ${ }^{2} \mathrm{~A}$ evidência de que o sistema imune, em particular o sistema imune adaptativo através dos linfócitos $T$, tinha um papel central no mecanismo da doença surgiu essencialmente com os resultados observados com DAB ${ }^{389} \mid \mathrm{L}-2$, um inibidor da IL-2 que provoca apoptose da célula T activadas, que demonstrou resolução clínica e histológica da psoríase. ${ }^{3}$ Consequentemente, durante anos a psoríase foi definida como uma doença do linfócito $T$ (inicialmente Th 1 e posteriormente Th 17) em que todas as outras células, essencialmente do sistema imune inato, eram apenas espectadores. Contudo, mais recentemente, outras linhagens celulares ganharam relevo na fisiopatologia da psoríase. São exemplo disso os neutrófilos, que levaram à publicação de artigos com títulos tão originais como "Sexy again: The renaissance of neutrophils in psoriasis" por Schön MP et al ou "Neutrophils' sexiness is independent of trendy fashion" por Mrowietz U. ${ }^{4,5} \mathrm{E}$ foram muitas outras as células que mostraram ter um papel mais ou menos relevante na psoríase, como as células dendríticas, macrófagos, mastócitos ou células linfóides inatas. ${ }^{6}$

Por outro lado, a natureza auto-imune da psoríase foi desde sempre motivo de grande debate. Apesar de estarem descritos inúmeros genes de suscetibilidade na psoríase, o alelo HLA-C*06:02 parece ser o principal; está presente em mais de $60 \%$ dos doentes, aumentando o risco de desenvolver psoríase em 9-23 vezes e influenciando a idade de início (mais precoce) e gravidade (mais grave) da doença. ${ }^{7}$ As moléculas da classe I HLA, são essenciais na apresentação de antigénios a linfócitos T CD8 + levando à sua activação e expansão. Aliás, no desenvolvimento das placas de psoríase, observa-se activação, expansão clonal e efluxo cutâneo de linfócitos T CD8 + provavelmente após apresentação de autoantigénios locais. ${ }^{8}$ Contudo, a verdade é que, apesar de importantes esforços, a natureza autoimune nunca foi demonstrada de forma inequívoca, não tendo sido identificado, até ao momento, nenhum autoantigénio responsável
Correspondência: Tiago Torres

Rua D. Manuel II, $s / n$, Serviço de Dermatologia

Centro Hospitalar do Porto, piso 1 - 4050-344 Porto, Portugal

Tel.: + 351226097429

E-mail: torres.tiago@outlook.com
Recebido/Received

24 Agosto/24 August 2016

Aceite/Accepted

25 Agosto/25 August 2016 


\section{Carta ao Editor}

pelo desenvolvimento de uma resposta auto-imune de linfócitos T CD8+ nas lesões de psoríase. Apesar disso, a investigação de possíveis autoantigénios tem sido o foco de vários grupos e, recentemente, foi sugerido que um peptídio antimicrobiano queratinocitário, a catelicidina (também conhecida por LL-37) poderia funcionar como um autoantigénio na psoríase. No entanto, grande parte dos doentes psoriáticos não parece apresentar células $T$ reactivas a esta molécula. ${ }^{9}$

Recentemente, dados extremamente interessantes foram publicados pelo grupo liderado por Jörg Prinz, que numa longa e complexa investigação, demonstrou que os melanócitos poderão ter um papel importante na fisiopatologia da psoríase, sendo o alvo de linfócitos T CD8+ auto-reactivos. ${ }^{10}$ Primeiro, observaram em estudos histológicos de placas psoriáticas uma elevada frequência de contacto directo entre linfócitos T CD8+ e melanócitos, com produção linfócitária de grânulos líticos direcionado aos pontos de contacto com os melanócitos, demostrando que estas células T CD8+ de pele psoriática reconheciam e respondiam a antigénios de melanócitos. Posteriormente, identificaram o antigénio ADAMTSL5 como o autoantigénio reconhecido por linfócitos $T$ provenientes de pele psoriática. Demonstraram por técnica de RT-qPCR e por imunoflorescência que apenas os melanócitos expressavam ADAMTSL5, e que nas lesões psoriáticas os linfócitos T CD8+ encontravam-se em contacto directo com os melanócitos ADMATSL5+. Finalmente, observaram que apenas os linfócitos T CD8+ de doentes psoriáticos produziam elevados níveis de IL-17A e INF-Y quando expostos a ADAMTSL5, o que não ocorria com linfócitos TCD8+ de indivíduos saudáveis.

Resumindo, a demonstração de células $T$ autorreativas específicas para ADAMTSL5 indicam que os melanócitos poderão ter um papel fundamental na iniciação da inflamação psoriática, além de apontarem para uma natureza autoimune da doença.

Curiosamente, o tipo de resposta das células $T$ não é citotóxico, observando-se aliás um aumento do número de melanócitos nas placas de psoríase, o que poderia explicar em parte a hiperpigmentação observada na resolução de lesões psoriáticas. Pelo contrário, as células T-citotóxicas promovem, estimulam e amplificam os mecanismos pró-inflamatórios com produção de IL-17.

Naturalmente que um longo caminho ainda está por percorrer para melhor entender o papel dos melanócitos na fisiopatologia da psoríase. Se é verdade que poderão ser essenciais na iniciação do processo inflamatória desta patologia, activando as células T produtoras de IL-17 através da apresentação do autoantigénio ADAMTSL5, também não deixa de ser verdade que o envolvimento dos melanócitos poderá ser apenas um fenómeno secundário.

Em forma de conclusão, podemos afirmar que nos anos
50/60 a psoríase era vista como uma doença do queratinócito, nos anos 80 o linfócito $T$ passou a ser o centro das atenções e mais recentemente os neutrófilos e os mastócitos passaram a ser vistos com centrais na fisiopatogenia da psoríase... e quando se pensava que não existiriam muitas mais células envolvidas nos mecanismos desta complexa doença, não é que o improvável melanócito aparece? Enfim, apetece dizer como Fernando Pessa... E esta, hein?!

Conflitos de interesse: Os autores declaram não possuir conflitos de interesse. Suporte financeiro: $O$ presente trabalho não foi suportado por nenhum subsídio ou bolsa.

Conflicts of interest: The authors have no conflicts of interest to declare. Financing Support: This work has not received any contribution, grant or scholarship.

\section{REFERÊNCIAS}

1. Lowes MA, Suárez-Farinãs M, Krueger JG. Immunology of psoriasis. Annu Rev Immunol. 2014; 32:227-55.

2. Carvalho S, Torres T, Selores S. tratamento da psoríase com agentes biológicos: para além dos inibidores do TNFa - o presente e o futuro. Rev Soc Port Dermatol Venereol. 2012; 70:299-310.

3. Gottlieb SL, Gilleaudeau P, Johnson R, Estes L, Woodworth TG, Gottlieb AB, et al. Response of psoriasis to a lymphocyte-selective toxin (DAB389IL-2) suggests a primary immune, but not keratinocyte, pathogenic basis. Nat Med. 1995; 1:442-7.

4. Schön MP, Broekaert SM, Erpenbeck L. Sexy again: The renaissance of neutrophils in psoriasis. Exp Dermatol. 2016 (in press).

5. Mrowietz U. Neutrophils' sexiness is independent of trendy fashion. Exp Dermatol. 2016 (in press).

6. Kim J, Krueger JG. The immunopathogenesis of psoriasis. Dermatol Clin. 2015; 33:13-23.

7. Nair RP, Stuart PE, Nistor I, Hiremagalore R, Chia NV, Jenisch $S$, et al. Sequence and haplotype analysis supports HLA-C as the psoriasis susceptibility 1 gene. Am J Hum Genet. 2006; 78: 827-51.

8. Conrad, C, Boyman O, Tonel G, Tun-Kyi A, Laggner U, de Fougerolles $A$, et al. a $1 \beta 1$ integrin is crucial for accumulation of epidermal T cells and the development of psoriasis. Nat Med. 2007; 13:836-42.

9. Lande R, Botti E, Jandus C, Dojcinovic D, Fanelli G, Conrad C, et al. The antimicrobial peptide LL37 is a T-cell autoantigen in psoriasis. Nat Commun. 2014; 5:5621.

10. Arakawa A, Siewert K, Stöhr J, Besgen P, Kim SM, Rühl $G$, et al. Melanocyte antigen triggers autoimmunity in human psoriasis. J Exp Med. 2015; 212:2203-12. 